\title{
Utilidad de las nuevas tecnologías en lengua alemana para universitarios Experiencias didácticas desde un enfoque constructivista
}

En el siguiente artículo exponemos experiencias educativas realizadas en la universidad de Castellón durante tres cursos consecutivos y que integran las nuevas tecnologías

e Internet en la enseñanza de alemán con óptimos resultados. En primer lugar nos centramos

en la videoconferencia y sus aplicaciones prácticas en clase de lengua alemana.

Describimos una experiencia realizada por video conferencia con otra universidad en Alemania. Especificamos el tipo de actividades que mejor se adaptarona la videoconferencia, así como los objetivos comunicativos y los beneficios que se derivaron del empleo de la misma. En segundo lugar ofrecemos una definición y explicación detallada de lo que es un proyecto e-mail, sin duda más factible en la mayoría de escuelas.

Posteriormente analizamos los resultados de esta experiencia y la influencia que tuvo en la motivación de nuestros alumnos.

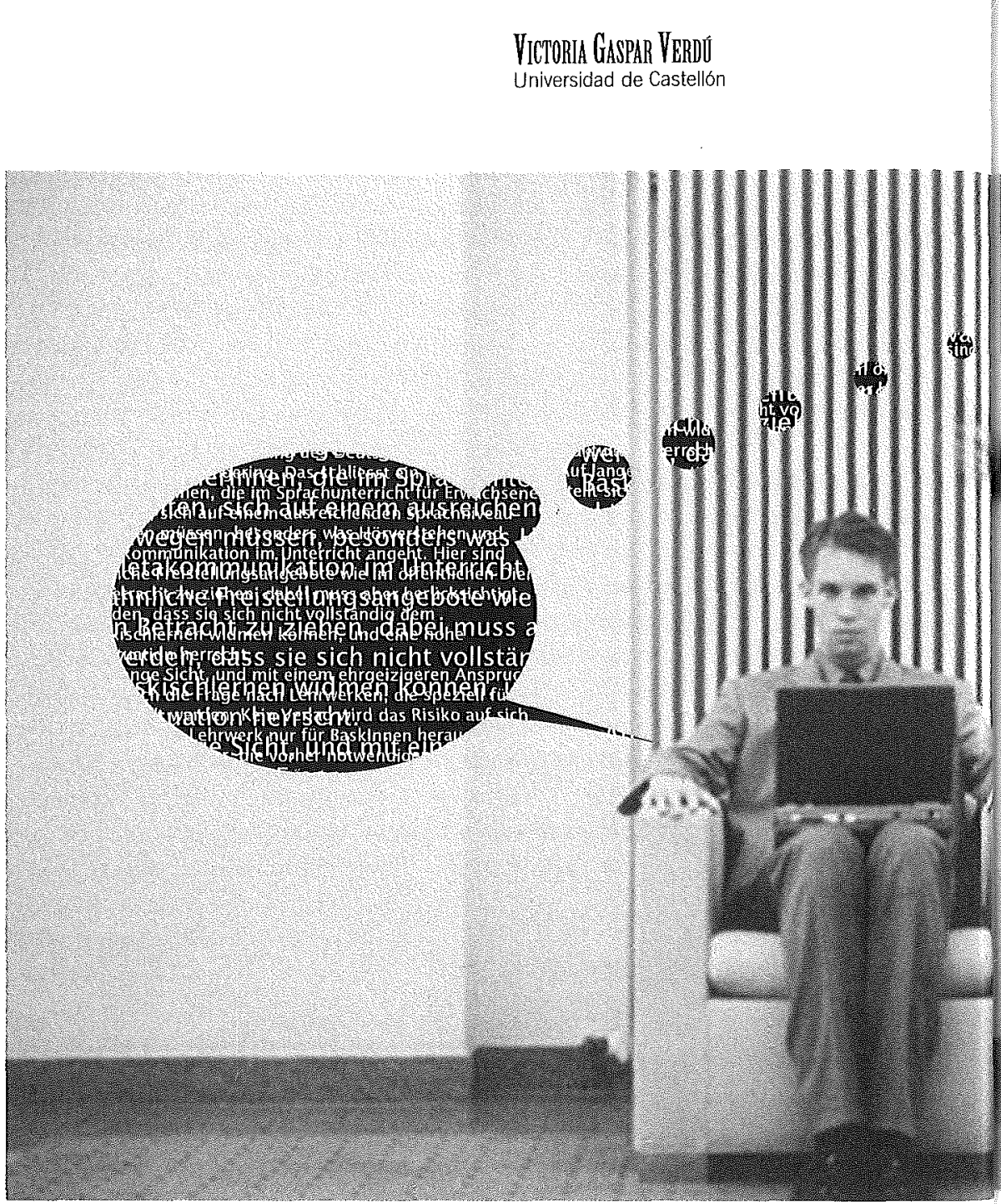

Ubicación de las Entre las teorías nuevas tecnologías en corrientes metodológicas: enfoque generales sobre adquisición de segundas lenguas, destacamos el enfoque comunicacomunicativo y tivo ya que ha teconstructivismo nido un especial protagonismo

desde mediados de los ochenta. El enfoque comunicativo, basado en las teorías de científicos y lingüistas de la talla de Piaget, Bru- ner o Vygotsky, se muestra afín al constructivismo y contrario al conductismo y al método audiolingual. Por ello concibe al alumno como sujeto activo en la construcción de su propio conocimiento y apuesta por el 'learning by doing', aprendizaje gracias al uso de la lengua y gracias a la integración de todas las destrezas lingüísticas, tanto activas como pasivas.

Tomando como base los principios establecidos en 1971 por el Consejo de Europa, y los principios funcionales-nocionales 
de Wilkins, el enfoque comunicativo establece en la enseñanza de lenguas como fin prioritario la comunicación y como principal objetivo el crear hablantes competentes, lo cual es perfectamente adaptable y compatible a las nuevas tecnologías ya que podemos plantear tareas y actividades comunicativas en parejas o entre grupos dando especial importancia a la capacidad para comunicar y transmitir información.

El constructivismo y el enfoque comunicativo introdujeron en los años $80 \mathrm{cam}$ -

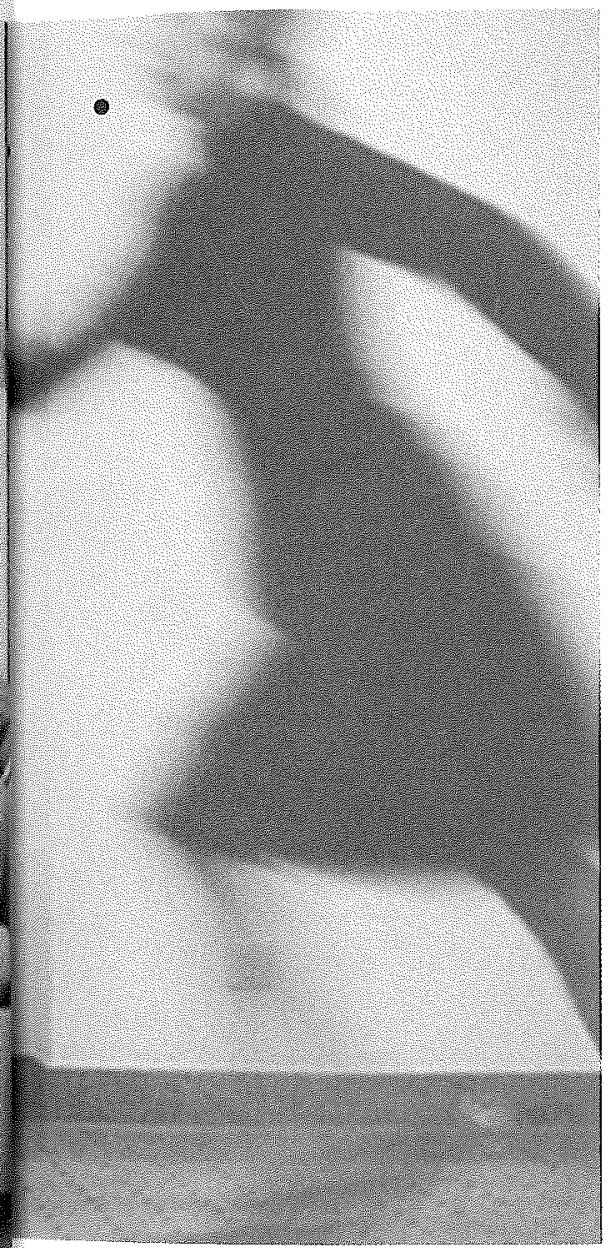

bios respecto a las corrientes metodológicas que les precedían, entre ellas el método gramática traducción, el método natural y el método directo. Aportaron la importancia del aprendizaje relevante y significativo, centrado en el alumno y en sus necesidades e intereses personales o profesionales, de nuevo todo ello adaptable a las nuevas tecnologías. En el aprendizaje significativo los alumnos relacionan sus conocimientos previos y producen una interacción cognitiva y social. Tanto el cons- tructivismo como el enfoque comunicativo consideran un factor fundamental la capacidad de los alumnos de asimilar, relacionar conocimientos y realizar hipótesis. Igualmente ambas corrientes admiten los errores no como actos indeseables o negativos, sino como parte integrante del proceso de aprendizaje. Entre las novedades que estas corrientes introducen, destacamos el empleo de estrategias metacognitivas o de 'aprender a aprender', una nueva aportación en el arduo camino del aprendizaje de lenguas extranjeras.

Dicha corriente atrajo el interés de los lingüistas en los años 80 y se basó en gran parte en el aprendizaje cooperativo, esto es con temarios, metodología y actividades comunicativas, actividades tipo 'information transfer', 'information gap', principio 'jigsaw', principio de dependencia de tareas y corrección de contenido. La aplicación de las nuevas tecnologías a estos principios implica un aprendizaje cooperativo y una metodología comunicativa. En definitiva, con el enfoque comunicativo los alumnos aprenden a intercambiar y transmitir información, al igual que hacemos con las nuevas tecnologías, emplearlas como herramientas de comunicación.

\section{Videoconferencias y proyectos tandem: sus aplicaciones en clase de lengua alemana}

Las nuevas tecnologías representan el futuro, aunque su utilización en clase actualmente aún es limitada. Gracias

a la introducción en nuestras clases de proyectos concretos vía e-mail, chat o web-cam se enfrentan tanto estudiantes como profesores a un contacto obligado con la tecnología. A continuación presentaremos experiencias y posibilidades didácticas realizadas con videoconferencia en enseñanza de lengua alemana, experiencias que actualmente están limitadas a algunos centros educativos debido a la escasez de medios informáticos. Además de la escasez de medios, respecto a la videoconferencia hay menos literatura, menos experiencias y menos libros de actividades enfocados a la enseñanza de lenguas, en comparación con los proyectos e-mail. No obstante, y a pesar de estos inconvenientes, la realización de experiencias y comunicación por videoconferen- cia, esto es con web-cams, sin duda nos abre nuevas posibilidades pedagógicas que hemos decidido experimentar en la enseñanza de lengua alemana.

Tras haber realizado un proyecto vídeoconferencia durante el curso lectivo 200304, pasamos a los alumnos un cuestionario de motivación y hábitos de estudio. En las respuestas aportadas por los alumnos, afirmaron que el contacto visual y simultáneo con los compañeros alemanes les hizo sentirse motivados hacia la asignatura. Reconocieron que pudieron contactar sin ningún problema por Internet con su compañero de proyecto. La mayoría incluso prefirió el contacto de videoconferencia al contacto por e-mail, y entre los motivos adujeron que era un contacto más inmediato y directo, no teniendo que esperar unos días a la respuesta. Alguno de ellos incluso añadió que la actividad le supuso menos tiempo de lo que pensaba. En líneas generales calificaron muy positivamente la innovación en la asignatura y afirmaron que les gustó el contacto visual directo con el compañero alemán. Incluso afirmaron haber establecido contacto con más frecuencia que cuando habían realizado previamente los proyectos e-mail.

La experiencia con el tele-tándem, esto es, conversación en parejas por vídeo- cámara, ha sido posible gracias al gran dispositivo de medios informáticos existente en ambos centros, tanto la universidad de Castellón como la escuela superior de tecnología de Bremervörde, centro con el cual establecimos contacto vía e-mail en el curso 2003-04. También ha sido necesario un trabajo previo de los tutores de ambos grupos, que previamente ya habían trabajado en un proyecto e-mail. El contacto entre los tutores a principio de curso y el intercambio constante entre ellos de informaciones sobre los objetivos del proyecto y elaboración de cuestionarios previos, hicieron posible plantear las primeras fases de tele-tándem para integrarlas en clase de lengua alemana.

El primer contacto -de presentación- entre ambos estudiantes cumplió tres fases:

\section{Preparación del encuentro en tele-tán-} dem. Ello incluye presentación de sí mismo, datos personales, aficiones, estudio, ciudad, tiempo libre y breve descripción de la 
familia. La preparación del encuentro puede ser practicada previamente con el profesor y ayudarse de un guión escrito con palabras clave.

2. Encuentro. Se recomienda que el primer encuentro dure no más de cinco minutos. Los alumnos utilizan como guión los puntos del cuestionario elaborado por los dos tutores. Tras las presentaciones, se puede terminar el primer contacto con algunas preguntas previas preparadas para el compañero y estableciendo una fecha para el próximo encuentro.

\section{Valoración del tele-tándem.}

Tras este primer contacto se repiten estos tres pasos, pero ya con un tema transversal del libro, para el cual los profesores hemos elaborado un cuestionario previo. La preparación oral del tema deberá realizarse previamente a cualquier contacto vía web cam con el fin de facilitar la expresión oral de los alumnos y que no se queden paralizados en el momento del contacto.

Se recomienda para el proyecto tándem emplear los temas transversales del libro de clase o algún tema que les resulte de interés. Esto implica una gran ventaja para el docente, ya que con la ayuda del mismo cuestionario previo para todos los alumnos, determinamos los puntos a comentar por ambos participantes. El profesor puede supervisar la exposición oral de todos los alumnos de su grupo, lo cual resulta más rápido si lo hacen por parejas, y preparar el encuentro. También se pueden emplear como tema de comunicación noticias de alcance internacional con la ayuda de prensa alemana o española en la red.

Dentro del tándem, los alumnos han encontrado muy motivador el intercambiar informaciones sobre su ciudad y entorno. Esta actividad la planteamos hacia final de curso, ya que con frecuencia los alumnos asocian la actividad a realizar en verano con la descripción geográfica de uno o varios lugares.

Entre los ejercicios más comunes que se pueden realizar con un proyecto tándem por vídeo conferencia, se encuentran los siguientes:

1 Dictados recíprocos. Gracias a la ayuda del profesor de lengua extranjera, que tutorizará esta actividad, los alumnos realizan dictados al nivel apropiado. Para ello es necesario un intercambio del texto del dictado por parte de los tutores, y facilitar vía e-mail o por escrito el texto original a todos los alumnos para que tealicen su propia corrección.

1 Intercambio de recetas. Esta actividad resulta, en el caso de la cultura alemana, muy adecuado para la época de Navidad o Adviento. En el caso de la cultura española se puede ampliar a otros meses. Resulta más eficaz si la combinamos con contenido gramatical, p. ej. con empleo de Partizip I o utilizando la voz pasiva.

I Aprendizaje intercultural. A los alumnos les resulta muy motivador el acercamiento a la vida y costumbres de otras culturas. El planteamiento de ciertos temas transversales a transmitir y narrar en lengua extranjera, siempre siguiendo un cuestionario previamente acordado, les hace ser conscientes de su propia cultura y costumbres. Temas como los estudios, la religión, la independen-

cia familiar, el noviazgo, etc. se realizarán con más seguridad si van acompañados de una sencilla tarea a cumplit, como encontrar las diferencias y similitudes entre la cultura de ambos países.

Desde la introducción del proyecto tándem, en la Universi-

dad de Castellón hay alumnos que acuden de modo voluntario y libremente una hora adicional a la semana para poder comunicar con sus compañeros alemanes por vídeoconferencia.

Consideramos cumplidos los objetivos comunicativos en cuanto a expresión oral, dado que los alumnos emplean más horas en la preparación de exposiciones orales y debido a ello ha aumentado su competencia comunicativa. Consideramos muy importante el hecho de que han cobrado consciencia de su propio progreso en expresión oral en lengua extranjera y de la utilidad de la lengua alemana. Por otro lado, consideramos cubierta la carencia comunicativa que se da en los manuales de clase, ya que el libro no es un compañero de conversación en lengua extranjera. Respecto a los bene- ficios que aporta el empleo de videoconferencia, los propios alumnos han considera do la experiencia con vídeoconferencia muy positiva porque les ha posibilitado un contacto personal con nativos y un contacto directo con la vida y cultura alemanas. Este hecho sin duda es innovador; dado que traspasa y va más allá de los libros en formato papel.

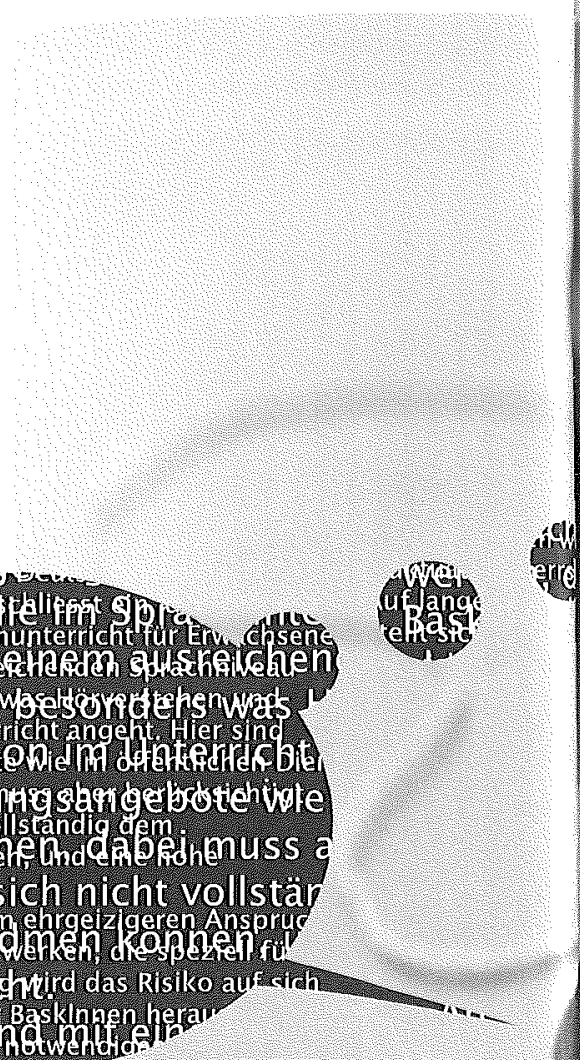


estos proyectos creamos hablantes competentes cuyo fin es la comunicación. En los proyectos e-mail son aplicables actividades tipo 'information transfer', que exigen de los estudiantes extraer información relevante de un texto y transmitirla al interlocutor. Asimismo son aplicables actividades tipo 'information gap', en las que un estudiante conoce exactamente la información que

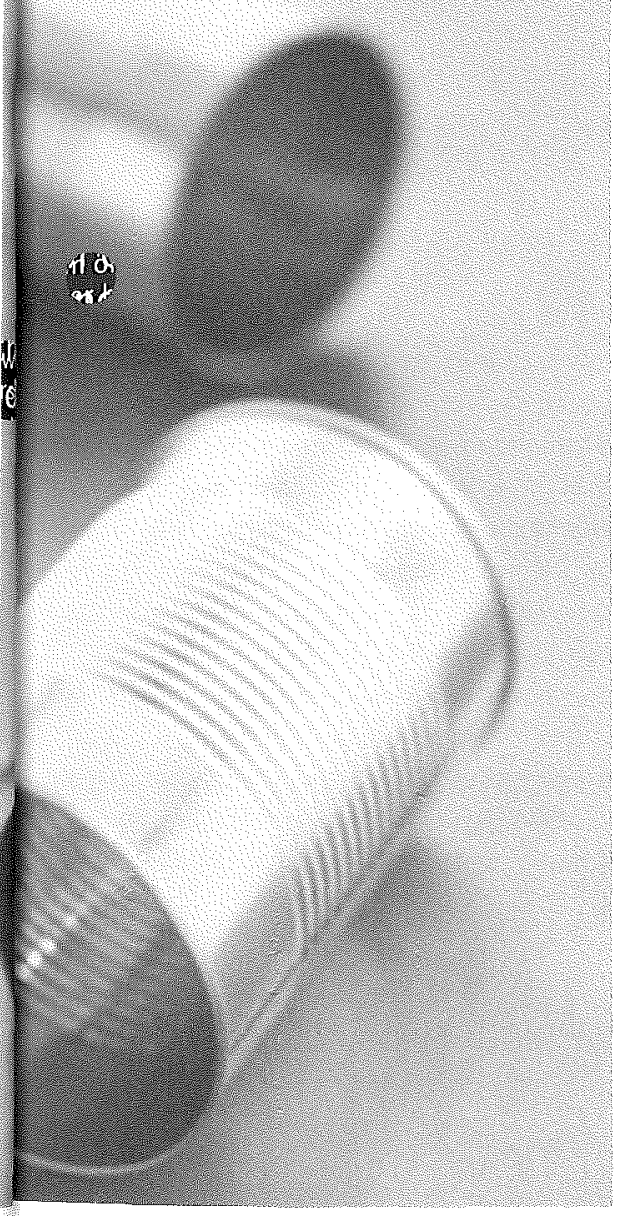

le falta a su compañero y viceversa, lo cual obliga a un intercambio de la información vía e-mail. Del mismo modo en los proyectos e-mail se cumple el principio de dependencia de tareas, que consiste en aplicar las cuatro destrezas a objetivos comunicativos claros, hecho que produce un aprendizaje significativo y efectivo. En estos proyectos la comprensión lectora y la expresión escrita son las destrezas más trabajadas, debiendo reforzar el profesor en clase la expresión

y comprensión oral. Asimismo, en la comunicación por e-mail se cumple el principio de corrección de contenido, consistente en el equilibrio entre corrección gramatical y fluidez oral o escrita. No podemos olvidar que en el enfoque comunicativo la perfección gramatical no es el objetivo primordial, tampoco en los proyectos e-mail. De hecho se presta mayor importancia a la capacidad de comunicar o competencia comunicativa que a la perfección gramatical, ahora bien, siempre sin subestimar esta última.

\section{Proyectos e-mail europeos para lengua alemana}

Las posibilidades de adscribirnos a proyectos e-mail desde España y para trabajar la lengua alemana son numerosas. En el marco europeo destaca el proyecto Comenius adscrito al programa universitario Sócrates-Leonardo de becas y estancias en el extranjero, ya que ofrece universidades alemanas que buscan otras universidades en Europa para una colaboración y un intercambio real de estudiantes de un país a otro. Las páginas oficiales las encontraremos en http://www.sokrates-leonardo.de/.

En esta dirección encontramos el enlace a los proyectos Comenius de cooperación europea, que tienen como objetivos la mejora y adquisición de lenguas extranjeras y la toma de consciencia europea de los estudiantes. Potencian el acercamiento entre culturas y realizan encuentros personales entre estudiantes universitarios de diversas naciones. Son proyectos coordinados y tutorizados con varios años de experiencia.

Consideramos que la oferta mejor adaptada a las necesidades e intereses de los estudiantes de alemán a nivel universitario es la página del Instituto Goethe, que ofrece en su portal http://www.goethe.org una conexión a chats, forums y e-mails. En ella hallamos conexión a proyectos con clases alemanas y una detallada descripción de los proyectos. Se acompaña de un formulario con datos sobre el nivel de lengua extranjera deseada, temas de interés, tiempo de realización, etc.

Resulta muy valiosa la información de seis proyectos realizados con éxito, los temas ofertados, tiempo de realización y ejercicios propuestos durante dichos proyectos, además de una detallada estructura de las clases, consejos didácticos y conexiones interesantes a diversas universidades y escuelas alemanas.

En www.bild-online.dk/evaluationsfragen .htm encontramos consejos sobre la corrección de e-mails, la importancia de manejar disquetes en estos proyectos, la motivación que produce en el grupo el intercambio de fotos de alumnos, su entorno, su ciudad, casa o escuela. Resultan muy útiles los datos sobre estructura y organización de un proyecto con buena aceptación entre los alumnos y resultados muy positivos. Más descripciones de proyectos con éxito encontraremos en www.englisch.schule.de/tipps, aunque en esta última no todos los proyectos son en lengua alemana.

\section{Esquema y La asignatura op- propuesta de tativa Lengua proyecto e mail de lengua alemana para universitarios Alemana ysu Li- teratura II se im- parte en el se- gundo curso de la Licenciatura} de Filología Inglesa, con una carga lectiva de sesenta horas. El carácter anual de ésta permite que sean tres las horas semanales dedicadas a su docencia. Al introducir un proyecto e-mail en esta asignatura estamos realizando una actividad comunicativa y de aprendizaje con otra clase del país de origen y con hablantes nativos de lengua alemana. En este proyecto entrarán en contacto dos grupos de edades e intereses similares en Alemania y España. La lengua vehicular puede ser el alemán o el español. También pueden alternarse ambas lenguas.

Basándonos en Schuller (2001), hemos realizado una variante de proyecto e-mail en lengua alemana para universitarios, que consta de las siguientes fases:

1. Coordinación previa entreprofesores, para acordar temas, tiempo de ejecución, cuestionario común. La necesidad de coordinación entre los profesores ya antes del comienzo del proyecto es un hecho demostrado. Es importante presentar y describir claramente al grupo de alumnos que tutorizamos, sus intereses o motivaciones y ver si se corresponden con las del otro grupo. Conviene acordar y coordinar los temas, intereses y objetivos de ambos grupos. El 
profesor será el encargado de recoger todas las direcciones e-mail de sus alumnos participantes y transmitirlas al e-mail del profesor del otro país. Una vez tengamos las direcciones de alumnos del otro grupo, las transmitimos y damos por iniciado el proyecto e-mail. Es positivo mantener comunicación constante con el profesor del intercambio y acordar fecha de envío, así como realizar un feed-back para el profesor en forma de cuestionario anónimo, donde nos transmitan lo que les ha gustado, lo que no les ha gustado y donde planteen propuestas de mejora para el próximo proyecto e-mail.

2. Presentaciones de los alumnos y su entorno, ciudad, escuela, familia, etc. Intercambio de fotos del grupo por correo ordinario o por e-mail.

Los alumnos encontrarán modelos para escribir sus primeros e-mails entre ellos en www.bild-online,dk/Aans. Los principiantes podrán practicar la competencia con temas interesantes en www.ejournal.eduprojects.net.

3. Introducción del tema. Envío de preguntas y respuestas. Búsqueda opcional de información en libros o internet. Responder cuestionario entregado por los profesores

Una propuesta sobre temas encontramos en www.englisch.schule.de/praxisti.htm.

Entre los más frecuentes se encuentran descripción de la ciudad donde viven, fiestas y costumbres navideñas, vida en familia, etc. Por ejemplo los alumnos del proyecto Bild consideran indispensable el tema 'yo y mi Hobby' y proponen como posibles temas música, cine, animales domésticos, vida diaria de los jóvenes en el link opiniones de los estudiantes, www.bildonline.dk/schueler. La misma preferencia de temas encontramos en www.englisch. schule.de/praxisti.htm. Es muy aconsejable que los profesores acuerden los puntos en que dividen el tema y cómo los trabajarán los dos grupos.

A continuación presentamos un proyecto e-mail realizado en la licenciatura de Filología Inglesa, concretamente en la asignatura Lengua Alemana II durante tres cursos consecutivos (2001-04). Se requieren conocimientos previos de alemán, ya que trabajaron con catálogos, folletos y páginas web en alemán.
Título: Meine Sommerferien.

Edad: Proyecto dirigido a grupo de estudiantes universitarios a partir de 18 años. Objetivos: Conocer aficiones y actividades de tiempo libre del compañero en Alemania.

Intercambiar experiencias vividas durante las vacaciones y mostrar lugares de vacaciones típicos del propio entorno. Reactivar estructuras gramaticales y vocabulario adquiridos durante el curso anterior.

Fases:

1 Presentaciones personales. Intercambio de fotos por correo normal o internet. Envío de fotos de la clase y de la web de Universidad www.uji.es

1 Introducción del tema. Envío de postales o páginas web con imágenes de nuestra ciudad www.castellon-costaazahar.com. Realizar visita virtual a ciudades de los compañeros alemanes. Lo ideal, según R.Donath (2003) oscila entre dos y tres semanas (www.englisch.schule.de) tipps_neu.htm). Destacamos el link recibidowww.meinestadt.de. y www.goethe.de/ $\mathrm{kug} / \mathrm{ges} / \mathrm{sur} / \mathrm{ks}$.

I Responder cuestionario comín elaborado por los dos profesores y enviado a los dos grupos. Descripción de cómo han pasado sus vacaciones, qué han hecho, con quién han estado, dónde y cuándo han viajado. Contar el contacto con amigos o algún grupo de su edad, cómo han llegado al lugar de vacaciones y si han podido utilizar una lengua extranjera. Relatar si han conocido a alguien interesante, si les ha sucedido algo divertido o si han practicado su deporte o hobby favorito.

1 Más preguntas y respuestas. Aprendizaje intercultural, comparación de gustos y costumbres de los españoles y de los de los alemanes. Diferencias y similitudes entre ambas culturas.

1 Resultadosy conclusiones. Valoración del proyecto. Qué consideras positivo o negativo del mismo. Despedidas hasta el próximo proyecto.

De las experiencias realizadas
Conclusiones, con proyectos eventajas e mail en lengua inconvenientes de alemana en la proyectos e-mail Universidad Jaullón durante los cursos 2001-04 se extrajeron las siguientes conclusiones

1 Completan el manual y las informaciones transmitidas en él.

1 Fomentan el empleo significativo de los conocimientos con hablantes reales en lengua extranjera.

1 Desarrollan la competencia comunicativa y posibilitan procesos de aprendizaje intercultural e interiorización de contenidos.

1 Elevan significativamente la motivación del alumnado por la asignatura. Concretamente les motiva conocer gente y hacer nuevos amigos.

De un total de 70 alumnos, 52 lo consideraron una experiencia positiva o muy positiva, es decir un $75 \%$ del total de los participantes. Los 18 alumnos restantes, esto es el $25 \%$, lo consideraron parcialmente realizado, no positivo o no respondieron. Entre las ventajas los alumnos destacaron la motivación y la participación generalizada de todo el grupo. Calificaron de muy positivo el intercambio de fotos personales en la fase de presentación, esto es al principio del proyecto. En posteriores contactos incluso se enviaron paquetes con souvenirs y dulces navideños de las ciudades de ambos grupos.

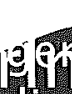

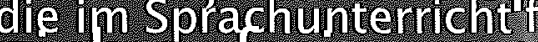
1.

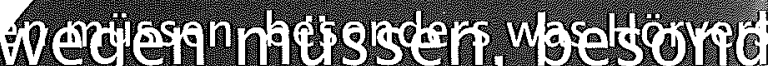

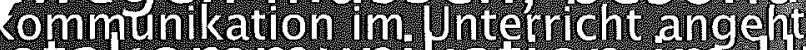

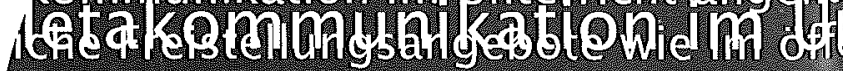

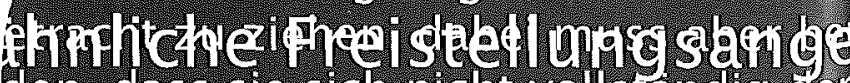

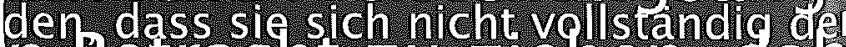

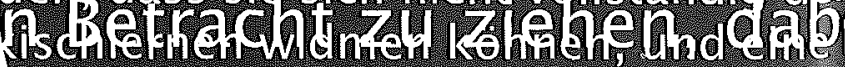

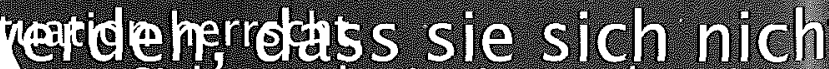

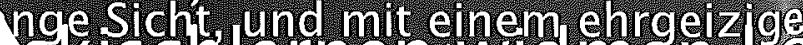

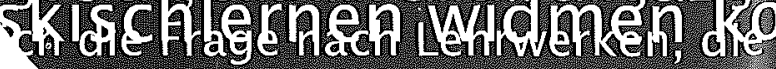

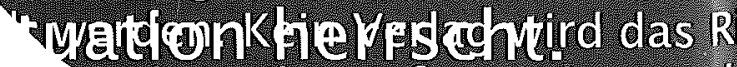

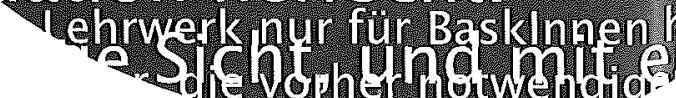


